cellular sodium ${ }^{2}$. Most of the nuclear chloride was removed by liver perfusion in vivo with a salt-free solution (experiment 2) and the concentration was considerably raised by perfusion in vivo with a chloride solution (experiment 3). Furthermore, after in vitro incubation of nuclei for $30 \mathrm{~min}$ (50 mg dry weight in $5 \mathrm{ml} .0 .075 \mathrm{M} \mathrm{SO}_{4}{ }^{2-}$, containing $\mathrm{Na}^{+}$and/or $\mathrm{K}^{+}$in different proportions), more than 90 per cent of the chloride originally contained in the nuclei was recovered in the incubation medium.

Existing data ${ }^{2}$ suggest that there are about $160 \mu$ equiv.

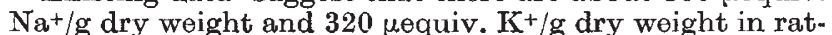
liver nuclei, as compared with about $200 \mu$ equiv. Cl-/g dry weight (Table 1). Therefore, about 40 per cent of nuclear alkali cations are neutralized by chloride. The deficit of anions which still remains is not covered by sulphate; analyses of the aforementioned liver fractions for total sulphur by the method of Tölg ${ }^{5}$ revealed $24 \mu$ equiv./g dry

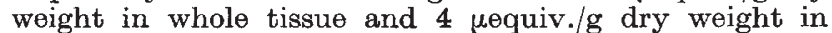
nuclei. Sulphate would only account for a fraction of the total sulphur content.

Nuclear chloride may be a component of the sodium space of the nucleus ${ }^{6}$, the function of which, however, is not as yet fully understood. Anyway, a distinct cellular site of high chloride concentration exists which is very similar to the concentration of chloride in the extracellular fluid. Information concerning the size and the significance of the chloride space in tissues and also the chloride potentials can be deduced from the data given in Table 1, which goes to show that cellular chloride is not distributed uniformly.

This work was supported by the Deutsche Forschungsgemeinschaft.

H. LANGENDORF

G. SIEBERT

K. Kesselring

R. Hannover

Department of Physiological Chemistry,

Johannes Gutenberg University, Mainz.

${ }^{1}$ Itoh, S., and Schwartz, I. L., Amer. J. Physiol., 188, 490 (1957).

2 Langendorf, H., Siebert, G., Lorenz, I., Hannover, R., and Beyer, R., Biochem. Z., 335, 273 (1961).

siebert, G., Biochem. Taschenbuch, edit. by Rauen, second ed., 2, 541 (Springer-Verlag, 1964).

- Beyermann, K., and Cretius, K., Clin. Chim. Aeta, 6, 113 (1961).

5 Tölg, G., Z. Anal. Chem., 194, 20 (1963)。

- Siebert, G., and Humphrey, G. B., Adv. Enzymol., 27, 239 (1965).

\section{Calf Thymus and Chicken Erythrocytes Nucleoproteins}

We have prepared a large series of nucleoproteins (DNP) from calf thymus by the method of Zubay and Doty $^{1}$ and, unlike these authors, have obtained amounts of gel (GDNP) that varied from 0 to 80 per cent. We were thus surprised to find that extraction of DNP from chicken erythrocytes by the same procedure regularly gave high percentages of gel; of six preparations, five gave 90 per cent or more GDNP.

The most important difference between the two series of preparations, aside from the origin of the starting materials, was the way in which they were obtained. The chicken blood was collected directly in the sodium chloride-versene used for washing the nuclei, but thymus could not be procossed immediately; it was frozen at variable times after the death of the animal, and was frequently processed after more or less prolonged storage in a refrigerator. Furthermore, the percentage of DNP gel was higher when enzymatic activity was stopped rapidly, as shown by the results with erythrocytes. This observation suggested that the soluble DNP (sDNP) might represent degraded material. To determine the nature of this degradation we prepared a new series of calf thymus nucleoproteins reducing the time before the tissue was frozen, in order to approach the conditions used in collecting the erythrocytes. We also kept the thymus for varying periods of time before starting the preparation, and noted the amounts of GDNP and SDNP obtained. We then undertook an analysis of the two types of DNP. Great care was taken to avoid mechanical degradation when the DNA was being extracted; its molecular weight was determined by light scattering in M sodium chloride.

Preparations made from thymus frozen 10-15 min after the animal had died produced between 92 and 98 per cent of GDNP. The DNA extracted from these DNP preparations had a molecular weight of $10 \cdot 5-15.5$ million.

Of three other preparations made from the same thymus, one, V123, had been homogenized $15 \mathrm{~h}$ earlier in $0.15 \mathrm{M}$ sodium chloride and left at $0^{\circ} \mathrm{C}$. All gave high percentages of gel, 97,96 and 92 per cent; but the molecular weight of the DNA from gel V123 was only 6.5 million, whereas the other two gave values of 10.9 million.

Three preparations made from three different lots of thymus yielded variable amounts of SDNP and GDNP. Thymus $V 127$, left $15 \mathrm{~h}$ at $23^{\circ} \mathrm{C}$ before processing, gave 42.4 per cent gel and $57 \cdot 6$ per cent soluble DNP, the molecular weight of the DNA extracted from DNP 127 gel was 8.2 million while that of $V 127$ soluble DNA was $5 \cdot 1$ million. Thymus V128, stored in a freezer for 3 weeks, gave 77.6 per cent gel, and $V 266$, frozen for 2 months, gave $76 \cdot 3$ per cent. The molecular weights of the gel DNAs were, respectively, 6.7 and 7 million; those of the DNAs from the two sDNP only $2 \cdot 8$ and $2 \cdot 4$ million. (The DNAs extracted from two lots of poorly washed erythrocyte nuclei, which had been allowed to stand for $24 \mathrm{~h}$ at $0^{\circ} \mathrm{C}$, also had very low molecular weights, 0.9 and 1 million.) Thus, in the sDNP that we have examined the molecular weight of the DNA has always been lower than that of the DNA from the corresponding gel, so that the SDNP must have undergone some nuclease action.

Chemical analysis of the SDNP and GDNP from thymus gave mean nitrogen : phosphorus ratios of 4.15 for the gels and 3.80 for the soluble fractions; a GDNP seems to be richer in protein than the corresponding SDNP. The lability of the SDNP was shown by its precipitation in $0 \cdot 15 \mathrm{M}$ sodium chloride; soluble DNP left $2-2.5$ times as many small and dialysable protein fragments in solution. This suggests that the protein of the SDNP has also been attacked enzymatically ${ }^{3,4}$ and that the resulting fragments are easily detached. In a DNP gel the protein fraction responsible for the constitution of a network between DNA molecules probably remains intact.

It should be emphasized that we have found no difference in the nitrogen : phosphorus ratio of the $S$ and $G$ fractions of chicken erythrocyte DNP and that this ratio is lower than that of the thymus gels. This suggests that the GDNP of thymus may be richer in some particular histone, perhaps active in gene regulation, that is respons. ible for the state of the gel, is more labile than other histone fractions, and is removed from sDNP. We are continuing these investigations in order to verify this hypothesis.

\section{Champagne}

\section{A. MAZEN}

Centre de Recherches sur les Macromolécules, Strasbourg.

1 Zubay, G., and Doty, P., J. Mol. Biol., 1, 1 (1959).

2 Bernardi, G., Champagne, M., and Sadron, C., Biochim. Biophys, Acta, 49, $1(1961)$.

3 Fredericq, E., Biochim, Biophys. Acta, 55, 300 (1962).

- Fredericq, E., Biochim. Biophys. Acta, 68, 167 (1963).

\section{Electron Microscopic Localization of Amines in Central Nervous Tissue}

Catecholamines have been detected in the central nervous system by means of a fluorescent technique ${ }^{1}$, and correlations have been made regarding the content of brain catecholamine and the presence of granules which reduce osmium tetroxide in nerve terminals ${ }^{2,3}$. No definitive electron microscopic localization of catecholamines has been achieved due to the lack of a specific fine-structural technique. 